\title{
Consumer-Oriented Drug Information Service Needs Assessment
}

\author{
Timothy K. Cheum ${ }^{1}$, Kejal V. Patel ${ }^{1}$, Rodney G. Richmond ${ }^{2}$ \\ ${ }^{I}$ Doctor of Pharmacy Candidate ${ }^{2}$ Associate Professor, Pharmacy Practice \\ Rodney G. Richmond, RPh, MS, CGP, FASCP, Department of Pharmacy Practice, Harding \\ University College of Pharmacy, 915 East Market Street, Box 12230, Searcy, AR USA 72149
}

\begin{abstract}
Federal legislation that has been introduced to amend the Social Security Act in order to provide for coverage of cognitive pharmacist services under the Medicare program in medically underserved communities. In the rural state of Arkansas this legislation would be well-received because a large portion of the state meets the criteria of a health professional shortage area. Considering the growing interest of using telecommunications as an alternative means of delivering healthcare services to medically underserved rural areas, a pharmacist-staffed consumer-oriented drug information service was explored. Over a 5-day period, 473 face-to-face consumer surveys were conducted in pharmacy and non-pharmacy settings in an urban cluster population center that serves the surrounding rural area. The survey was designed to determine whether or not consumers had a perceived need for a drug information service that was independent from and supplemental to services provided by their pharmacist. Results reveal that $71 \%$ of participants surveyed did not perceive a need for medication information that was supplemental to that provided by their pharmacist. When queried regarding the likelihood of using a drug information service if one was available their response was neutral, and they became less likely if a fee was associated with the service. While the results are not conclusive and cannot be generalized as to whether a consumer-oriented drug information service would contribute to improving patient care, the survey suggests that this telepharmacy service is not perceived as being needed by the public.
\end{abstract}

KEYWORDS - Consumer medication information, Drug information center, Patient education, Telepharmacy

\section{INTRODUCTION}

Under federal law in the United States, despite their extensive education and training on the use of drug therapy, pharmacists are not recognized as healthcare providers. While strides have been made to recognize pharmacists at the state level, this lack of provider status has severely limited pharmacists' formal contribution to improving patient care. On March 11, 2014, H.R. 4190 was introduced in the United States House of Representatives, legislation that would amend the Social Security Act to provide for coverage of cognitive (non-drug product) pharmacist services under the Medicare program in medically underserved communities (i.e. settings located in a health professional shortage area, medically underserved area, or medically underserved population).[1]

Arkansas, situated in the southern United States, is a state with 75 counties that has a largely rural population (45\%). All or parts of 73 counties have been identified as medically underserved, while 55 counties have officially designated health professional shortage areas. ${ }^{[2]}$ Recent statistics show there are 867 residents in Arkansas for every one primary care doctor, whereas in the U.S. overall there are 631 residents for every one primary care doctor. ${ }^{[3]}$ In contrast, in Arkansas there are approximately 4,500 pharmacists represented in all 75 counties which equates to a favorable 658 residents for every one pharmacist. ${ }^{[4]}$ Clearly, legislation that affords pharmacists provider status coupled with the size and distribution of the pharmacist workforce could help meet the needs of patients in rural Arkansas.

As a means of delivering pharmacy services in medically underserved rural areas, some states have seen the development and implementation of telepharmacy services. While the provision of pharmacy services via telecommunications has been described to include a variety of clinical and dispensing functions, in Arkansas it has principally revolved around remote order entry with drug regimen review in a hospital setting. ${ }^{[5,6]}$ One service that would be readily adaptable to a telepharmacy application and could be provided on a large scale are pharmacist-based drug information services.

Drug information centers have been a staple in pharmacy practice since their inception. However, their traditional role has been principally focused on serving healthcare providers, almost to the exclusion of consumers. The objective of this survey was to explore the perceived need for a consumer-oriented drug information telepharmacy service that is unrelated to pharmacy dispensing services in rural Arkansas. 


\section{METHODS}

We conducted face-to-face consumer surveys over a 5-day period in an urban cluster population center of approximately 21,000 inhabitants which serves as the economic epicenter for the surrounding rural area. ${ }^{[7]}$ Survey participants were recruited from both pharmacy and non-pharmacy settings, including six chain pharmacies, five independent pharmacies, and two non-pharmacy commercial establishments. All unique respondent identifiers were purged from the aggregate data upon completion of data collection and prior to analysis. This survey received an exempt status from the Harding University institutional review board. Participation was voluntary without inducement and informed consent was given.

Upon agreeing to participate in the survey, the purpose of a consumer-oriented drug information service was first described to each respondent as: "The purpose of a drug information service is to answer your medication-related questions by providing you with objective, unbiased information in an effort to promote safe and cost-effective medication use." Then, participants were administered a 2-3 minute survey designed to determine whether or not consumers had a perceived need for a drug information service that was independent from and supplemental to services provided by their pharmacist. The survey instrument consisted of a combination of five closed-ended, Likert scaled, and multiple-choice questions. On a scale of 1 to 5 , with 1 being highly-likely and 5 being highly-unlikely, participants were asked regarding the probability that they would use a consumer-oriented drug information service if one were available, and separately the probability that they would use the service if a fee was involved. Finally, the survey collected information on the types of drug-related questions the consumer would most commonly have, as well as the preferred method by which the consumer could pose and receive responses to information requests. Descriptive statistics were compiled expressing results as percentages for each question in the survey.

\section{RESULTS}

A total of 473 participants provided evaluable responses to the survey (Table 1). The total number of surveys completed was nearly evenly distributed across pharmacy $(n=252,53 \%)$ and nonpharmacy $(n=221,47 \%)$ settings. However, more individuals participated in the survey from a chain pharmacy setting $(179,71 \%)$ when compared to an independent pharmacy setting $(73,29 \%)$.

Table 1. Perceived Need for Consumer-Oriented Drug Information

\begin{tabular}{|c|c|c|c|}
\hline \multirow{2}{*}{ Survey Setting } & \multirow{2}{*}{$\begin{array}{c}\# \\
\text { Respondents } \\
\end{array}$} & \multicolumn{2}{|c|}{ Information Needed } \\
\hline & & Yes & No \\
\hline All Settings Combined & 473 & $135(29 \%)$ & $338(71 \%)$ \\
\hline Pharmacy & 252 & $64(25 \%)$ & $188(75 \%)$ \\
\hline Independent & 73 & $17(23 \%)$ & $56(77 \%)$ \\
\hline Chain Drugstore & 179 & $47(26 \%)$ & $132(73 \%)$ \\
\hline Non-Pharmacy & $221 *$ & $71(32 \%)$ & $150(68 \%)$ \\
\hline
\end{tabular}

*Two participants in a non-pharmacy setting did not answer this question

When asked "Do you have a need personally for information about your medication that would supplement information provided by your pharmacist?", overall only $29 \%$ responded in the affirmative with the vast majority (71\%) indicating they did not have a personal need. When responses were separated according to survey setting (see Table 1), there was a slightly greater perceived need by participants queried in a non-pharmacy setting (32\%) versus those asked inside a pharmacy $(25 \%)$.

Table 2. Consumer's Likelihood of Using a Drug Information Center (Scaled Response: 1 = Highly-Likely to 5 = Highly Unlikely)

\begin{tabular}{lcc}
\hline \multicolumn{1}{c}{ Survey Setting } & \# Respondents & $\begin{array}{c}\text { Mean } \\
\text { Response }\end{array}$ \\
\hline All Settings Combined & 472 & 2.9 \\
Pharmacy & 249 & 3.0 \\
Independent & 72 & 2.9 \\
Chain Drugstore & 177 & 3.1 \\
Non-Pharmacy & 223 & 2.8 \\
\hline
\end{tabular}

*Three participants in a pharmacy setting did not answer this question 
In response to the question "How likely would you be to use a consumer-accessible drug information service?", the overall mean response on a scale of $1-5$ was an ambivalent 2.9 (mean $=3$, mode $=3$; see Table 2 ). It was expressed by some respondents that this type service might be beneficial to access at a time their pharmacy was closed. Participants were even less receptive to the concept when asked "How likely would you be to use a consumer-accessible drug information service if there was a fee for the service?", with an overall mean response on a scale of $1-5$ of 3.5 (see Table 3 ).

Table 3. Consumer's Willingness to Pay for Drug Information Services

\begin{tabular}{lccc}
\hline \multicolumn{1}{c}{ Survey Setting } & \# Respondents & Mean & Median \\
\hline All Settings Combined & 472 & 3.5 & 4 \\
Pharmacy & 251 & 3.7 & 4 \\
$\quad$ Independent & 73 & 3.5 & 4 \\
Chain Drugstore & 178 & 3.7 & 4 \\
Non-Pharmacy & 221 & 3.2 & 3 \\
\hline
\end{tabular}

*Three survey participants across all survey settings did not answer this question

Summarized in Table 4 are the preferred modes of access if respondents were inclined to use a consumer-oriented drug information service. Finally, the types of drug-related questions consumers anticipated they would most commonly ask are depicted in Fig. 1.

Table 4. Preferred Mode of Access

\begin{tabular}{lc}
\hline \multicolumn{1}{c}{ Survey Setting } & \% \\
\hline Telephone & $35 \%$ \\
Online Submission & $30 \%$ \\
Live Conversation & $18 \%$ \\
US Mail & $15 \%$ \\
Fax & $2 \%$ \\
\hline * Four participants in a pharmacy setting
\end{tabular}

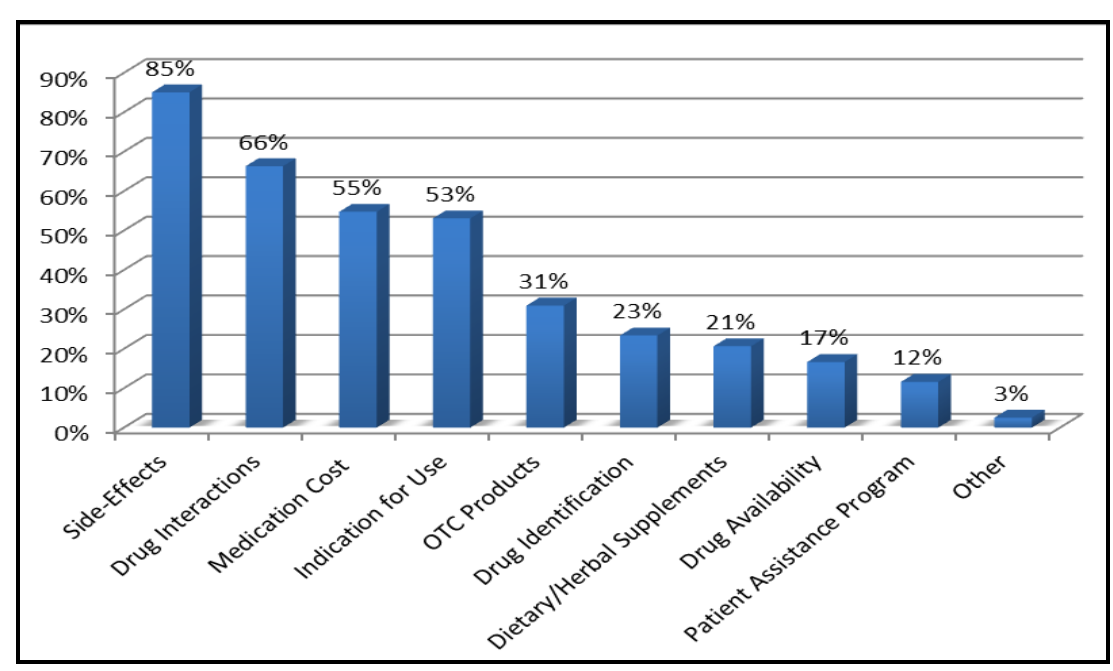

Fig. 1 Types of drug information most commonly anticipated 


\section{DISCUSSION}

A strict interpretation of the results indicates the public: (1) does not perceive there to be a need for an independent consumer-oriented drug information service that is not connected in some way with their pharmacy-related services; (2) is ambivalent in terms of their likelihood of using a service if one were available; and (3) would further be less likely to use a service if a fee was involved. These results, while somewhat surprising, remain valuable because absent a reason that compels them to do so, it is clear the public is not likely to voluntarily access the resources of a consumer-oriented drug information service. Beyond this, the results perhaps raise more questions than they provide answers.

Although a measure of satisfaction was not factored into the survey, the results could indicate the respondents' drug information needs were being adequately met by their pharmacist. Alternatively, there could be some sampling bias related to location because more than half the surveys were taken inside a pharmacy. However, any effect the location had on the responses was small because, even though there was a tendency for non-pharmacy participants to have a greater perceived need for consumer-oriented drug information services, the different between settings was $<10 \%$. Finally, cost should not have been a factor in influencing answers to the other questions because the question related to fee-based services was the last question asked.

Despite the survey findings, it is known that the majority of patients have unmet drug information needs and the lack of awareness about proper medication use and associated risk factors has been identified as potentially accounting for some rural health disparities. ${ }^{[8]}$ This is evidenced by poor medication adherence and issues with drug safety, problems that are only compounded in patients living in medically underserved areas. Several key medication-related health needs in residents in rural Arkansas have been identified. Arkansans have been shown to have a high prevalence of heart disease, stroke and diabetes, chronic disease states that require intensive pharmacotherapy. With respect to health maintenance, Arkansas has an adolescent immunization rate that is lower than the national average. Further, rural Arkansans are more likely to struggle with low health literacy. ${ }^{[9]}$ Each of these represents problem areas where pharmacists can use their unique skills to enhance patients' health.

\section{CONCLUSIONS}

Whether or not patients are in the best position to determine whether supplemental drug information is needed, under the scenario surveyed they would be the ones making the decision to initiate contact with the service described. While these findings do not speak to whether a consumer-oriented drug information service would contribute to improving patient care, the survey indicates a consumer-oriented drug information telepharmacy service is not perceived as being needed by the public.

\section{REFERENCES}

[1] United States Congress. H.R.4190: To amend title XVIII of the Social Security Act to provide for coverage under the Medicare program of pharmacist services. Accessed on October 6, 2014 from https://www.congress.gov/bill/113thcongress/house-bill/4190.

[2] United States Department of Health and Human Services. Shortage designation: health professional shortage areas and medically underserved areas/population. Accessed on October 2, 2014 from http://hpsafind.hrsa.gov/HPSASearch.aspx.

[3] Arkansas Department of Health. Arkansas's big health problems and how we plan to solve them: state health assessment and improvement plan, 2013. Accessed on October 6, 2014 from http:// www.healthy.arkansas.gov/aboutADH/Documents/Accred/ARHealthReportHealthProblems.pdf.

[4] Arkansas Board of Pharmacy. Licensee Information. Accessed on October 6, 2014 from http://pharmacyboard.arkansas.gov/Pages/default.aspx.

[5] Bynum A, Hopkins D, Thomas A, Copeland N, Irwin C. The effect of telepharmacy counseling on metered-dose inhaler technique among adolescents with asthma in rural Arkansas. Telemed J E Health. 7(3), 2001 Fall, 207-17.

[6] Casey M, Elias W, Knudson A, Gregg W. Implementation of telepharmacy in rural hospitals: potential for improving medication safety, December 2008. Accessed on October 8, 2014 from http://rhrc.umn.edu/ wpcontent/files_mf/telepharmacy.pdf.

[7] United States Census Bureau. 2010 Census urban and rural classification and urban area criteria. Accessed on October 2, 2014 from https://www.census.gov/geo/reference/ua/urban-rural-2010.html.

[8] Balamurugan A, Rivera M, Sutphin K, Campbell D. Health communications in rural America: lessons learned from an arthritis campaign in rural Arkansas. J Rural Health. 23(3), 2007 Summer, 270-5.

[9] Centers for Disease Control and Prevention. Arkansas: burden of chronic diseases. 2008. Accessed on October 9, 2014 from http://www.cdc.gov/chronicdisease/states/pdf/arkansas.pdf. 